\title{
Microbiomes of Top and Sub-Layers of Semi-Arid Soils in North-Eastern Nigeria Are Rich in Firmicutes and Proteobacteria with Surprisingly High Diversity of Rare Species
}

\author{
Mwajim Bukar'1, Oluwole Sodipo², Karim Dawkins ${ }^{3}$, Roberto Ramirez ${ }^{3}$, \\ Jummai T. Kaldapa', Martha Tarfa ${ }^{1}$, Nwadiuto Esiobu ${ }^{3}$ \\ ${ }^{1}$ North-East Zonal Biotechnology Centre of Excellence, University of Maiduguri, Maiduguri, Nigeria \\ ${ }^{2}$ Biochemistry Department, Faculty of Science, University of Maiduguri, Maiduguri, Nigeria \\ ${ }^{3}$ Biological Sciences Department, Microbial Biotech Laboratory, Florida Atlantic University, Boca Raton, FL, USA \\ Email:bkmwajim@gmail.com,nesiobu@fau.edu
}

How to cite this paper: Bukar, M., Sodipo, O., Dawkins, K., Ramirez, R., Kaldapa, J.T., Tarfa, M. and Esiobu, N. (2019) Microbiomes of Top and Sub-Layers of Semi-Arid Soils in North-Eastern Nigeria Are Rich in Firmicutes and Proteobacteria with Surprisingly High Diversity of Rare Species. Advances in Microbiology, 9, 102-118. https://doi.org/10.4236/aim.2019.91008

Received: December 10, 2018

Accepted: January 26, 2019

Published: January 29, 2019

Copyright $\odot 2019$ by author(s) and Scientific Research Publishing Inc. This work is licensed under the Creative Commons Attribution International License (CC BY 4.0).

http://creativecommons.org/licenses/by/4.0/

\begin{abstract}
Borno state is the second largest state in Nigeria with over 70,000 square kilometers of diverse ecosystems including parts of the fertile Lake Chad basin. However, more than $2 / 3$ of this landmass is threatened with drought, advancing desertification and degraded soils. Most restoration efforts involve revegetation, which in the past has met with limited success. Microbial communities of soils play a pivotal role in soil fertility and plant cover. We conducted the first metagenomic amplicon sequencing study, comparing two soil depths to determine whether soil bacteria abundance and diversity in the harsh bare soils were sufficient to sustain greening efforts. The goal was to glean insights to guide microbial inoculant formulation needed in the region. Samples from top $(0-15 \mathrm{~cm})$ and sub $(16-65 \mathrm{~cm})$ soils were collected from five strategic locations in the state. Using next generation Illumina sequencing protocols, total DNA extracted directly from the soils was sequenced and analyzed by QIIME. Metadata collected from site showed scorching temperatures of over $46^{\circ} \mathrm{C}$, near zero moisture level and a pH of about 6 for top soil. At $65 \mathrm{~cm}$ depth, the temperature averaged $32^{\circ} \mathrm{C}$ with a $\mathrm{pH}$ of 5 and significantly higher soil moisture of $0.1 \%$. The bacterial community structure was unexpectedly very diverse at both soil depths samples, recording a ChaO1 index ranging from 909 to 4296 and a Shannon diversity range of 3.54 to 6.33 . The most abundant phyla in both soil depths were the Firmicutes and Proteobacteria; however the relative abundance of composite lower taxa was strikingly different. Operational taxonomic units and diversity indices were highest
\end{abstract}


for top soils and were dominated by members of resilient groups of Actinobacteria, Firmucutes, Acidobacteria and numerous other less well-known taxa whose individual relative abundance did not exceed $3 \%$ of total population. The high diversity and richness of Proteobacteria (at $65 \mathrm{~cm}$ depth), some of which are key to soil fertility, suggest that revegetation efforts could be improved by shifting the gradient of these microbiota upwards using shades and micro-irrigation. Soils in semi-arid regions in Nigeria contain numerous operational taxonomic bacterial groups with potential thermophilic and drought genetic resources to be mined. Microbial community structure beneath the top soil appears stable and should be the target sample for the assessments of climatic change impact on microbial community structure in environments like this.

\section{Keywords}

Microbiomes, Semi-Arid Soils, Microbial Community Structure, Soil Bacteria, Soil Fertility, Top-Soil, Re-Vegetation, Proteobacteria, Firmicutes, Sub-Surface, OTU

\section{Introduction}

The soil microbial community structure in arid and semi-arid regions is generally poorly characterized [1] [2] although the increasing understanding of the impact of land degradation due to desertification has brought these ecosystems to a global focus [3]. Studies have observed significant losses of biodiversity due to desertification in both terrestrial and aquatic ecosystems on local and global scales [4] - a change that has shown to profoundly impair the functioning of natural ecosystems [5] [6]. These losses in diversity also significantly impact on the productivity and function of the arid ecosystem negatively and are estimated to affect the livelihood of 250 million people in the developing world [7] [8].

Several factors have been shown to influence the microbial diversities in the arid and semi-arid soils, mostly across a large-scale geographic region [3] [7], with $\mathrm{pH}$, moisture, organic carbon content, nature of vegetation cover, and agricultural practices being the major determinants of microbial diversity [2] [6] [7].

For most soils, microbes exist throughout the soil profile, being most abundant in surface soils, the rhizosphere of plants, and around macropores [9] [10]. Macropores are channels formed by plant roots, earthworms, and other soil biota and are often lined with organic matter that sustains microorganisms. The occurrence, prevalence and diversity of soil microbes is well correlated with organic matter and is highest in the top $10 \mathrm{~cm}$ and decline with depth. Interestingly, Thulani et al. (2015) noted that bacterial composition was most variable in the surface horizons whereas lower down the communities were relatively simi$\operatorname{lar}[11]$. 
Borno state is the second largest state in Nigeria with over 70,000 square kilometers of diverse ecosystems including parts of the fertile Lake Chad basin. However, more than $2 / 3$ of this landmass is semi-arid characterized by variable rainfall, drought and desertification. In addition, rising temperatures and many anthropogenic factors such as over-grazing and poor water use efficiency have led to land degradation, subjecting millions of peasant farmers and pastoralists to immense economic hardship and social vulnerability. Vast areas of land lay bare without plant cover, exposed to extremely high temperatures and wind impact. These harsh climatic and anthropogenic factors have resulted in the loss of about $90 \%$ of the sixth largest fresh water lake in the world with its consequent insecurities.

Nearly all national and international mitigation strategies for the complex regional problems recommend revegetation and reforestation to reduce land degradation and establish proper grazing traditions. Meanwhile, the success of such projects (often undertaken by non-professionals with limited success) is largely dependent on the availability of soil micro-fauna and microbiota which regulate soil fertility. The top-soil in some areas visited by the authors is very dry with little evidence of organic matter and no trace of plant-life for as far as the eye could see. So, the first critical step is to define the diversity and prevalence of bacteria in the highly degraded soil and beneath the bare surface soil; and to use it to predict the potential outcome of revegetation projects. And since these soils have not been studied, the potential for uncovering new groups of bacteria exist. In fact, the nature of soil microbial diversity relative to depths in semi-arid regions has been poorly studied. Studies describing microbial populations in arid soils tend to focus on microbes of degraded top soil, omitting data from underlying profiles which could become useful in formulating revegetation guidelines and environmental management. In this study, weanalyzed the bacterial profiles and diversity in a district of the semi-arid region of Borno state Nigeriaand hypothesized that microbial abundance and diversity will be significantly impacted by soil depth, driven by environmental variables like $\mathrm{pH}$, temperature and moisture content. Understanding the microbial diversity in layers beneath top soil compared could provide insight into the resilience of the belowground microbial niches and allow predictions on soil fertility and type of microbial inoculant consortia needed for successful revegetation projects.

\section{Materials and Methods}

\subsection{Sampling}

Soil samples were collected from five (5) uncultivated locations using a sterile calibrated soil auger and hand trowel (for samples that were to fine and loose to be sampled by the auger). Global positioning system (GPS) coordinates of precise sampling sites were noted. The soil surface was cleared of plant materials (where they occurred) and top soil of $0-15 \mathrm{~cm}$ (I) and $16-65 \mathrm{~cm}$ (II) depths were collected and placed in sampling bags. At each of the five locations A, B, C, 
$\mathrm{D}$ and $\mathrm{E}$, composite samples were collected within a five-meter radius and stored at $-20^{\circ} \mathrm{C}$ until further analysis. Figure 1 displays the sampling sites.

Soil temperature at both depths was measured in the field using a digital thermometer while $\mathrm{pH}$ and Moisture contents were determined using a $\mathrm{pH}$ meter/a standard soil $\mathrm{pH}$ protocol and drying at $80^{\circ} \mathrm{C}$ respectively [12]. Table 1 presents a detailed description and abiotic parameters of the study locations. Replicate samples collected from the same site and depth were combined and properly mixed before DNA extraction.

\subsection{DNA Extraction}

DNA was extracted from $10 \mathrm{~g}$ of soil using MOBIO PowerMax ${ }^{\oplus}$ Soil DNA isolation kit (Mo Bio Laboratories, Inc. CA, USA). Extraction was carried out according to manufacturer's instruction. DNA was concentrated into $50 \mu \mathrm{L}$ volume from the $10 \mathrm{~mL}$ elution volume using salt-ethanol precipitation [13]. Extracted DNA was quantified using Nanodrop (Thermos Scientific, USA) and the integrity checked on 1\% agarose gel electrophoresis [12]; to ensure DNA fragmentation was minimal during extraction.

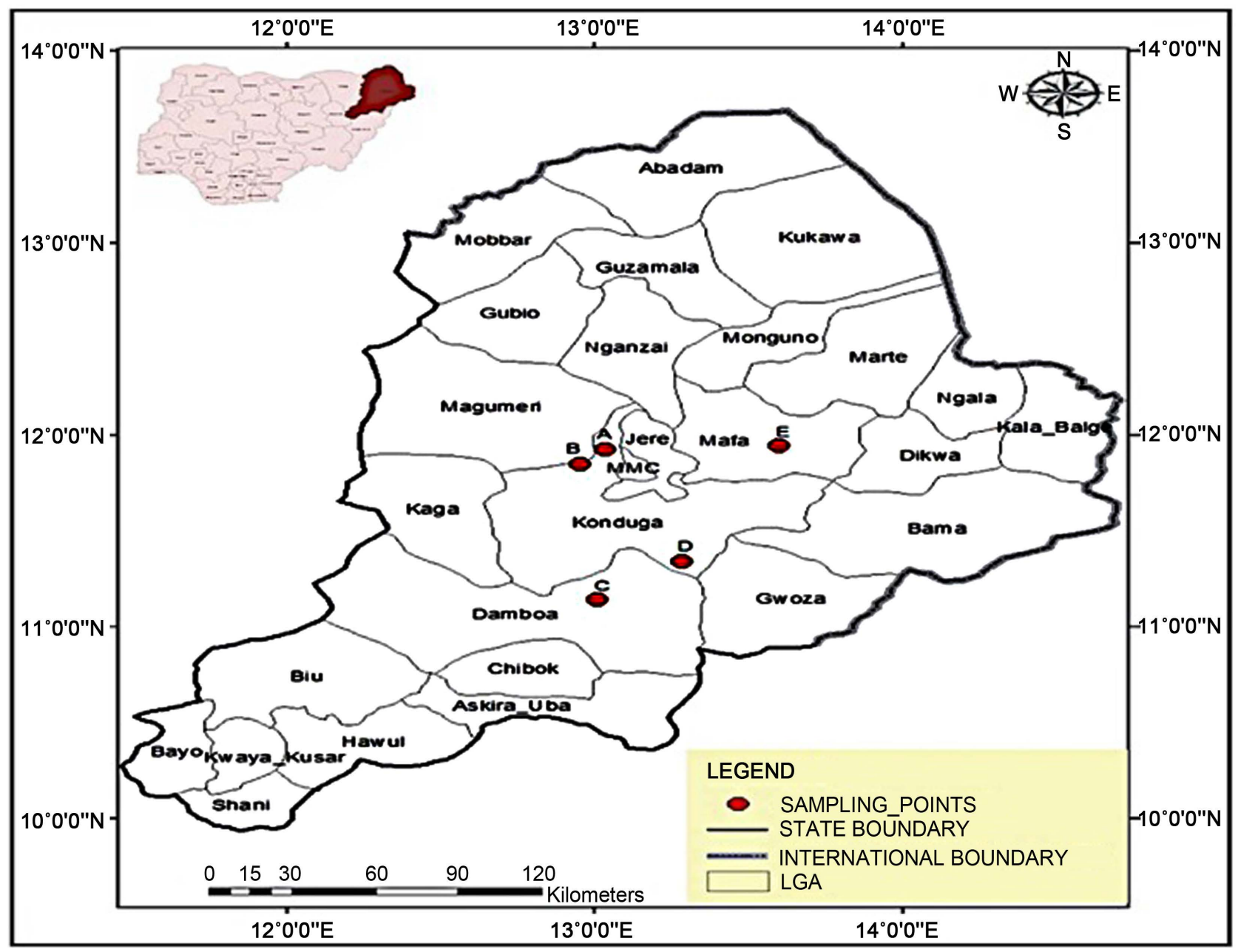

Figure 1. Map of sample collection sites. Samples were collected at locations A, B, C, D, and E indicated by red points on the map. 
Table 1. Description of sampling depth, GPS location and abiotic conditions at the Semi-arid soils of Borno state studied.

\begin{tabular}{|c|c|c|c|c|c|c|}
\hline $\begin{array}{l}\text { Sampling } \\
\text { Site }\end{array}$ & $\begin{array}{l}\text { Soil } \\
\text { Depth } \\
(\mathrm{cm})\end{array}$ & $\begin{array}{l}\text { Coordinates } \\
\text { Lat }\left(\mathrm{N}^{\prime}\right), \\
\text { Long }\left(\mathrm{E}^{\prime}\right)\end{array}$ & $\begin{array}{c}\text { Description of } \\
\text { study sites }\end{array}$ & $\mathrm{pH}$ & $\begin{array}{c}\text { Moisture } \\
(\%)\end{array}$ & $\begin{array}{l}\text { Soil } \\
\text { Temp } \\
\left({ }^{\circ} \mathrm{C}\right)\end{array}$ \\
\hline AI & $0-15$ & $\begin{array}{c}\mathrm{N} 11^{\circ} 55^{\prime} 22^{\prime \prime}, \\
\mathrm{E} 013^{\circ} 01^{\prime} 54.44^{\prime \prime}\end{array}$ & $\begin{array}{l}\text { Soft, sandy soil. } \\
\text { Very fine, } \\
\text { red-orange color }\end{array}$ & $6.3^{\mathrm{a}}$ & $0.060^{\mathrm{b}}$ & $45^{\mathrm{a}}$ \\
\hline AII & $16-65$ & same & $\begin{array}{c}\text { As above, not as } \\
\text { loose }\end{array}$ & $5.2^{\mathrm{b}}$ & $0.37^{\mathrm{a}}$ & $30^{\mathrm{b}}$ \\
\hline BI & $0-15$ & $\begin{array}{c}\mathrm{N} 11^{\circ} 50^{\prime} 53^{\prime \prime} \\
\mathrm{E} 012^{\circ} 57^{\prime} 17^{\prime} 45^{\prime \prime}\end{array}$ & $\begin{array}{l}\text { Soft, sandy soil. } \\
\text { Very fine, } \\
\text { red-orange color }\end{array}$ & $6.2^{\mathrm{a}}$ & $0.070^{\mathrm{b}}$ & $44^{\mathrm{a}}$ \\
\hline BII & $16-65$ & Same & $\begin{array}{c}\text { As above, not as } \\
\text { loose }\end{array}$ & $5.5^{\mathrm{b}}$ & $0.40^{\mathrm{a}}$ & $31^{\mathrm{b}}$ \\
\hline CI & $0-15$ & $\begin{array}{l}\text { N11 }{ }^{\circ} 10^{\prime} 32.5^{\prime \prime}, \\
\text { E01301'25.50" }\end{array}$ & $\begin{array}{l}\text { Soft, sandy soil. } \\
\text { Very fine, } \\
\text { red-orange color }\end{array}$ & $6.4^{\mathrm{a}}$ & $0.08^{\mathrm{b}}$ & $43^{\mathrm{a}}$ \\
\hline CII & $16-65$ & Same & $\begin{array}{c}\text { As above, not as } \\
\text { loose }\end{array}$ & $5.0^{\mathrm{b}}$ & $0.35^{\mathrm{a}}$ & $33^{\mathrm{b}}$ \\
\hline DI & $0-15$ & $\begin{array}{l}\mathrm{N} 11^{\circ} 25^{\prime} 45.5^{\prime \prime}, \\
\mathrm{E} 013^{\circ} 21^{\prime} 53.0^{\prime \prime}\end{array}$ & $\begin{array}{l}\text { Soft, sandy soil. } \\
\text { Fine texture, } \\
\text { red-orange }\end{array}$ & $6.1^{\mathrm{a}}$ & $0.080^{\mathrm{b}}$ & $47^{\mathrm{a}}$ \\
\hline DII & $16-65$ & Same & $\begin{array}{c}\text { As above, not as } \\
\text { loose }\end{array}$ & $5.1^{\mathrm{b}}$ & $0.38^{\mathrm{a}}$ & $30^{\mathrm{b}}$ \\
\hline EI & $0-15$ & $\begin{array}{l}\text { N11 }{ }^{\circ} 48^{\prime} 50^{\prime} 5^{\prime \prime}, \\
\text { E013 } 41^{\prime} 25.10^{\prime \prime}\end{array}$ & $\begin{array}{l}\text { Soft, sandy soil. } \\
\text { Fine texture, } \\
\text { brown-red with } \\
\text { scanty shrub } \\
\text { vegetation nearby }\end{array}$ & $6.3^{\mathrm{a}}$ & $0.075^{\mathrm{b}}$ & $46^{\mathrm{a}}$ \\
\hline EII & $16-65$ & Same & $\begin{array}{c}\text { As in E1. Not as } \\
\text { loose }\end{array}$ & $5.2^{\mathrm{b}}$ & $0.32^{\mathrm{a}}$ & $32^{\mathrm{b}}$ \\
\hline
\end{tabular}

Numbers on the same column with different letters are significantly different at $\mathrm{p}=0.01$.

\subsection{Polymerase Chain Reaction for $16 \mathrm{~S}$ rRNA Gene}

Bacterial 16S rRNA gene was amplified using a universal primer [14] that targets a 566 bp segment (V3-V4) of the gene. Forward; (341F) 5'-cct acgggaggcagcag-3' Reverse; (907R) 5'-ccgtcaattcmtttgagttt-3' PCR was carried out in a $50 \mu \mathrm{L}$ reaction containing 1.25U Taq Polymerase (Roche Diagnostics GmbH, Germany) in standard buffer containing $2.5 \mathrm{mM} \mathrm{MgCl}_{2}, 0.2 \mu \mathrm{M}$ each of forward and reverse primers, $0.2 \mu \mathrm{M}$ dNTPs and $0.4 \mathrm{mg} / \mathrm{ml}$ BSA. PCR was performed in a thermocycler (Mastercycler nexus, Eppendorf, Germany) using the following conditions; initial denaturation at $95^{\circ} \mathrm{C}$ for 5 min followed by 35 cycles of $95^{\circ} \mathrm{C}$ for 30 secs, $52^{\circ} \mathrm{C}$ for 30 secs and $72^{\circ} \mathrm{C}$ for $1 \mathrm{~min}$ followed by final extension at $72^{\circ} \mathrm{C}$ for 5 min. Agarose gel electrophoresis was run on PCR products to confirm amplification of the target sequence. 


\subsection{Next Generation Sequencing}

Sequencing was carried out on Illumina MiSeq platform following the protocol described in [12] [15]. The extracted DNA from the soil were amplified in a triplicate reaction of $25 \mu \mathrm{L}$ for each of the ten (10) soil samples with the $515 \mathrm{f} / 806 \mathrm{r}$ primer set that amplifies the V4-V5 region of the 16S rRNA gene. The primers contain the appropriate Illumina adapters and the reverse primer contains a 12-bp error-correcting barcode sequence unique to each sample. After amplification, the amplicons were cleaned up and the triplicate reactions were pooled together in equimolar concentrations and sequenced on Illumina MiSeq2000.

\subsection{Data Analysis and Visualization}

Analysis of the sequenced data was carried out using Quantitative Insight into Metagenomics (QIIME 1) tool [16]. The sequences were demultiplexed and filtered to remove singletons. Taxonomic analysis of the domains of the sequenced reads were assigned to OTUs using a closed-reference OTU picking protocol in QIIME, where BLAST was applied to search sequences against a subset of the RDP filtered at $97 \%$ identity. Sample AI accidentally fell during sequence library preparation. Empty tube was rinsed with a buffer to salvage sample, but the sequence reads were below one hundred. As a result, AI and the corresponding $65 \mathrm{~cm}$ depth (AII) were excluded from statistical analysis.

Reads were assigned to OTUs based on their best hit to the database at $\geq 97 \%$ sequence identity. Taxonomic identification was assigned to each read by accepting taxonomy string of the best matching RDP sequence. Samples were rarefied to at 80,000 cut off before further analysis. Alpha diversity (Chao1) and beta diversity (weighed and unweighted UniFrac PCoA plots) were created in QIIME after rarefaction while PARMANOVA test was used to compare variance. The BIOM format file obtained from QIIME was imported to MEGAN6 (version 6.10.6) [17] and Phinch [18] for visualization.

\section{Results and Discussion}

\subsection{Richness and Diversity of Bacteria and Archaea in Semi-Arid Soils}

The Sequence Read Archive accession number for this study is SRP159541 while the individual sample sequence tags in the (NCBI) range from SRS3737345 - 53. Table 2 shows the range of sequence reads obtained from the study sites and their corresponding Sequence Read Archive (SRA) accession numbers. It is difficult to equate the 16S SSU amplicon sequence reads to actual bacteria and archaea numbers for many reasons; amplified DNA could have come from both dead and viable cells, enormous variability in the number of this chronometer gene amongst the vast range of resident prokaryotes in soils and finally the possibility of high wind transport of propagules in this ecosystem. Nevertheless, the comparative yield was similar in all sites (except E) and was about the same for both top and sub soil samples. In most agricultural soils, the top soil usually 
Table 2. Total sequence reads and the sequence repository accession numbers.

\begin{tabular}{cccc}
\hline $\begin{array}{c}\text { Sampling } \\
\text { Site }\end{array}$ & $\begin{array}{c}\text { Total Sequence Reads } \\
\text { Top Soil Depth }(0-15 \mathrm{~cm})\end{array}$ & $\begin{array}{c}\text { Total Sequence Reads } \\
\text { Sub-Surface Soil Depth } \\
(16-65 \mathrm{~cm})\end{array}$ & $\begin{array}{c}\text { NCBI Accession } \\
\text { Numbers }\end{array}$ \\
\hline A & 38 (excluded) & 82,349 & SRS3737345 \\
B & 96,419 & 79,921 & SRS3737346-7 \\
C & 83,011 & 95,122 & SRS3737348-9 \\
D & 80,120 & 97,741 & SRS3737350-51 \\
E & 127,956 & 374,962 & SRS3737352-3 \\
\hline
\end{tabular}

holds several folds more bacteria than deeper surfaces.

An analysis of the relative abundance and nature of the bacterial community structure revealed a strikingly unexpected high diversity in both soil depths investigated. These soils have not been previously characterized using culture-independent molecular protocols, thus, this study pioneered the establishment of sequence-based data on the current bacterial community structure both at the top soil $(0-15 \mathrm{~cm})$ and that of sub-surface depth of $65 \mathrm{~cm}$. Each of the composite samples (except site AI) contained at least 25 taxonomic units (Figure 2), with more than 40 different phylogenetic taxarecovered from all the samples.

Chaol estimates shows that the abundance of unique species and OTUs are significantly higher in the top soil than the sub-soil except for site E (Table 3). The alpha diversity matrices in each soil depth as well as the beta diversity indices were unexpectedly high with top soils showing higher diversity than the sub-soils. Distribution of species appears to overlap across the different depths (Shannon and Simpson), resulting in only significant differences in the diversity indices with respect to relative abundance. The "richness" observed in the top soil may not be unrelated with previously identified high relative abundance of Firmicutes and Actinobacteria in the top soil and its related high number of OTUs (Figure 2 and Figure 3).

Rarefaction curve (Figure 3) plots and compares species density (abundance) and diversity in the samples.

These data suggest that only a few bacteria display highly elevated richness while most species occur in low numbers. This agrees with the operational taxonomic grouping (Figure 4) which attributes only about $50 \%$ of functional activities to four hardy phyla (Firmicutes, Actinobacteria, Acidobacteria and Bacteroidetes, while the rest of OTUs consist of groups of species occurring in relatively very low numbers. The survival strategy of so many species (if viable) under the harsh temperatures and near zero moistures underscores the need to invest in exploring this niche for rare biological and genetic resources. It moreover points to the resilience of the ecosystem and its capacity to host agricultural and horticultural vegetation with adequate technology.

It is noteworthy that the weighted PCoA plots (Figure 5) clusters the top soil sequences separate from the sub-surface soils, highlighting the differences 


\section{Sample Sites}

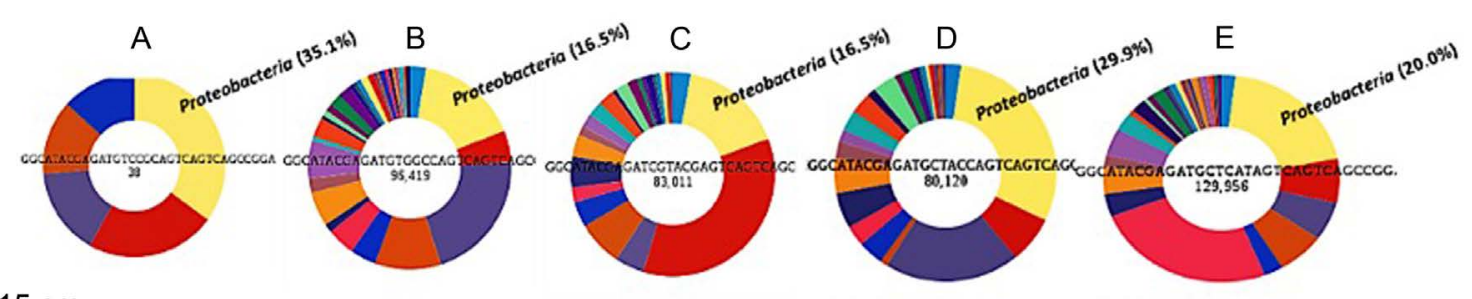

Top Soil 0 - $15 \mathrm{~cm}$

2 savnemy in that

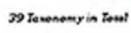

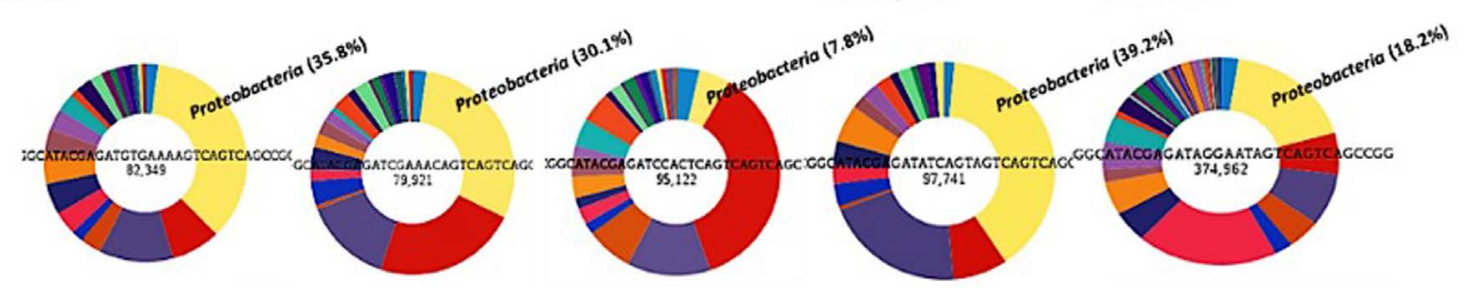

Sub Soil $16-65 \mathrm{~cm}$

Figure 2. Pie chart of the high diversity of prokaryotes displayed as relative abundance (\%) of phylogenetic taxa at the various depths $($ TPS $=$ Top soil $0-15 \mathrm{~cm}$ : SS = Subsoil $16-65 \mathrm{~cm}$ ) of sampling sites A, B, C, D and E in semi-arid soils of Borno State, Nigeria.

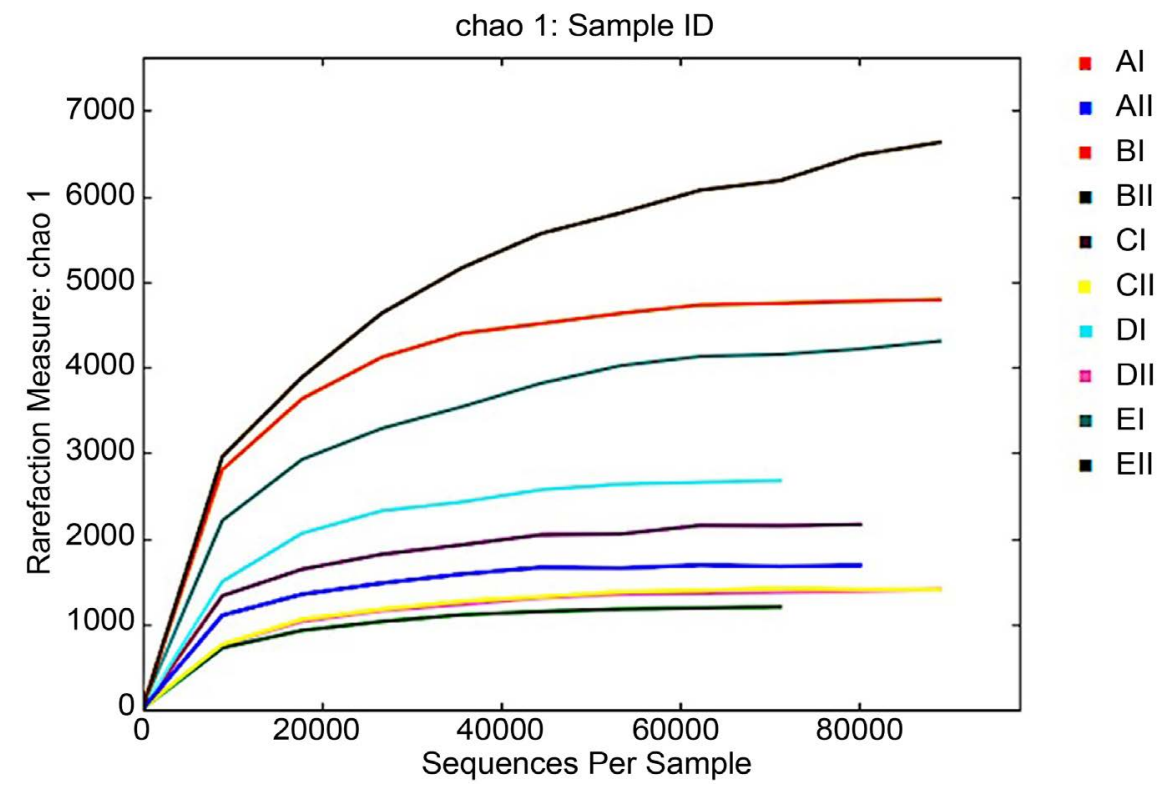

Figure 3. Chao1Rarefaction curves showing relatively high species density (richness) per sample site and soil depth within samples B, C, D and E.

between the phylotypes found in the top soil and sub-soil at lower taxonomic ranks.

\subsection{Phylogenetic Diversity and Significance}

A total of forty (40) distinct phyla (not shown) of bacteria were identified, of which Proteobacteria and Firmicutes on the average were the most abundant numerically (Figure 2). Earlier reports [3] [19] found that Proteobacteria, Acidobacteria and Actinobacteria were among the widespread and abundant phyla 


\section{NUMBER OF OTUS}

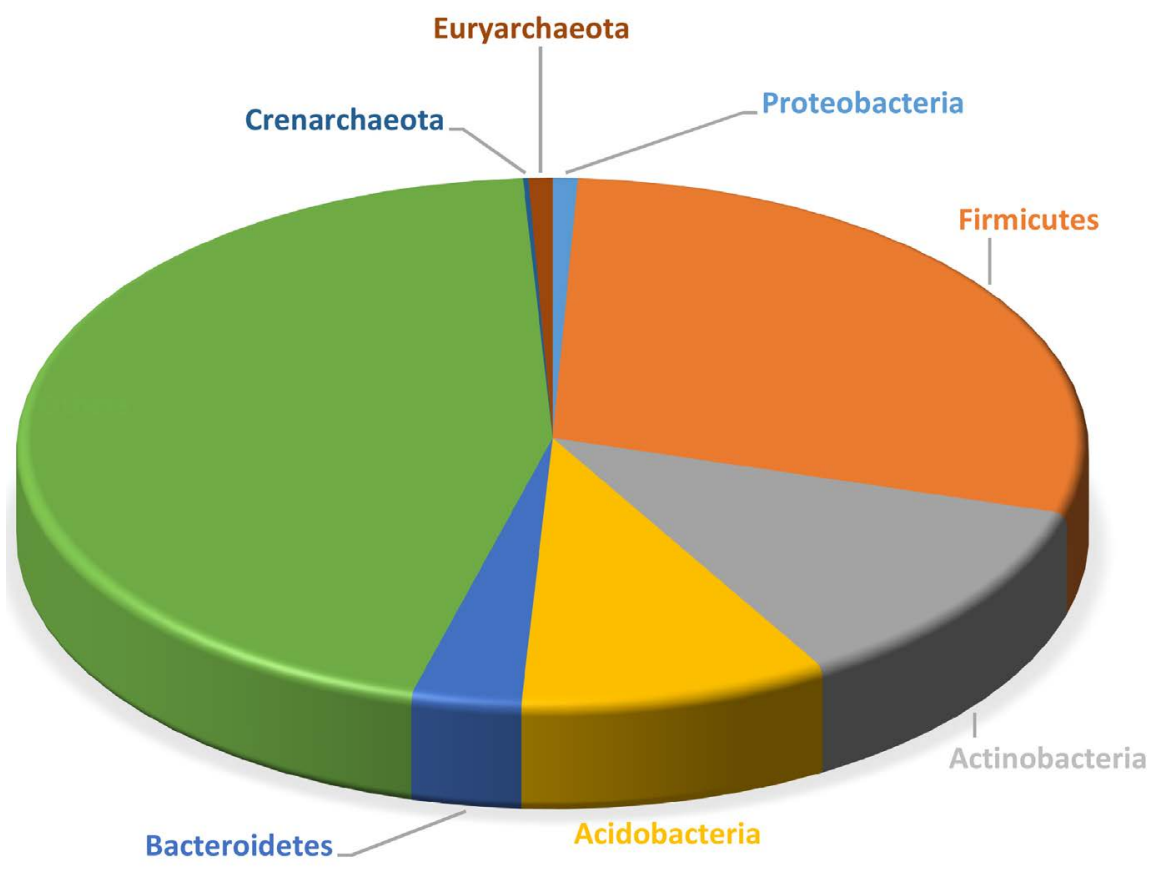

Figure 4. Operational taxonomic units (OTUs) of all bacteria and archaea obtained from 0 - $65 \mathrm{~cm}$ depth of five sampling sites reveal only a handful of known operational taxa while more than $40 \%$ (green) of the operational units in the semi-arid soils belong to organisms of relatively low relative abundance or of unknown identity.

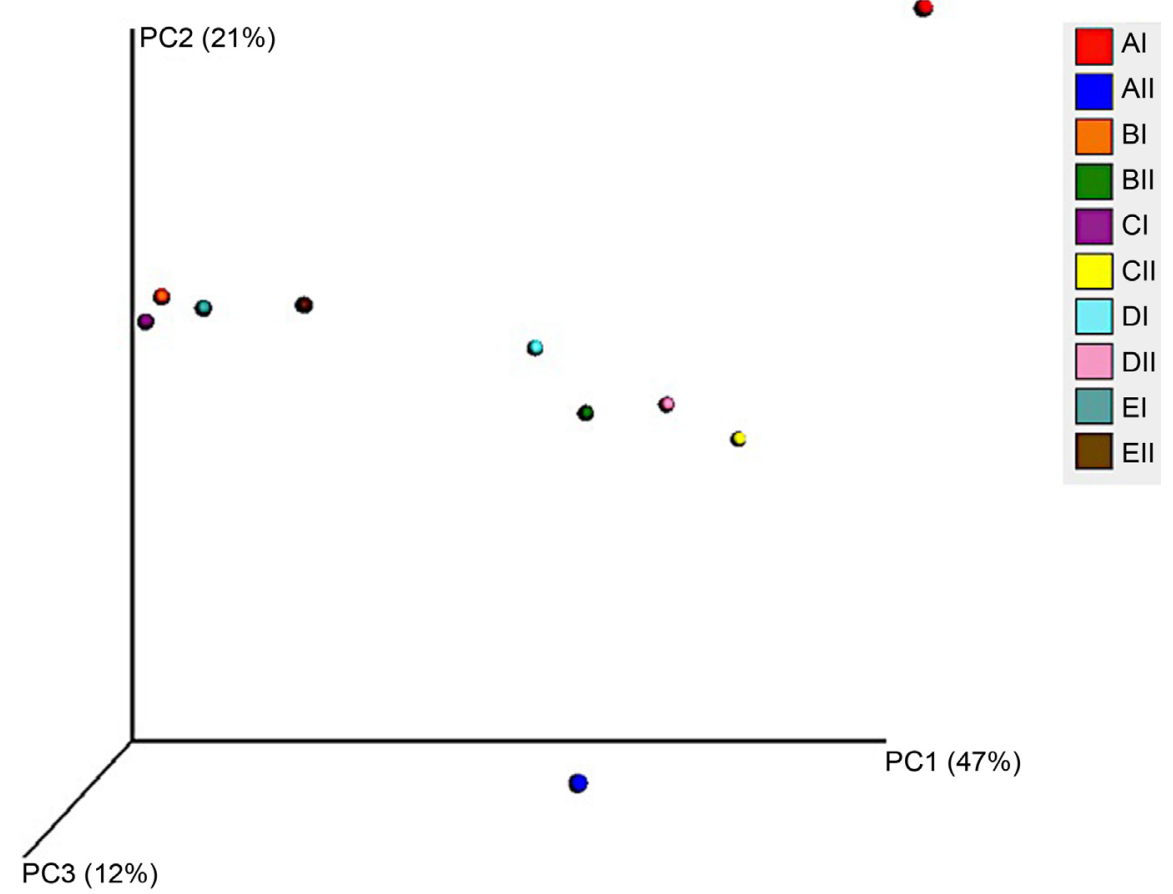

Figure 5. Beta diversity plots of weighted UniFrac for all samples. Each point represents sequences from a sampling location. Top (BI, CI, DI, and EI) and sub-soil (BII, CII, DII, EII) microbiota cluster differently but on same axis suggesting distinct but strong similarity of the niches. 
Table 3. Comparative analysis of species diversity and richness within and between the top soil and sub-soil samples from a semi-arid region using multiple indices.

\begin{tabular}{|c|c|c|c|c|c|}
\hline Site & & Chao 1 & Shannon & Simpson & No. OTUs \\
\hline \multirow{2}{*}{ B } & Top Soil & 2900.85 & 6.33 & 0.95 & 2243.0 \\
\hline & Sub-Soil & 909.00 & 3.54 & 0.76 & 672.0 \\
\hline \multirow{2}{*}{$\mathrm{C}$} & Top Soil & 1432.00 & 4.05 & 0.84 & 1027.0 \\
\hline & Sub-Soil & 1120.66 & 3.79 & 0.84 & 819.0 \\
\hline \multirow{2}{*}{$\mathrm{D}$} & Top Soil & 1612.43 & 4.60 & 0.88 & 1253.0 \\
\hline & Sub-Soil & 995.22 & 4.16 & 0.87 & 758.0 \\
\hline \multirow{2}{*}{ E } & Top-Soil & 2500.92 & 5.13 & 0.90 & 2052.0 \\
\hline & Sub Soil & 4296.01 & 5.89 & 0.93 & 3565.0 \\
\hline
\end{tabular}

of bacteria in similar soils. It is remarkable that in this study, Acidobacteria (2.3\%) and Actinobacteria (3.3\%) were in the top ten most abundant groups with very low relative numerical richness but accounted for about $20 \%$ of the operational taxonomic units (Figure 4). A recent study on global drylands showed that microbial community in the drylands are markedly distinct in both composition and function from other microbiomes and show higher level of diversity than expected [9]. Other studies on global drylands suggest a progressive decrease in microbial diversity with increasing aridity [20] but these changes were not studied relative to depths or at the subsurface. Although our study shows that the overall microbial composition and diversity at the phylum level did not differ significantly between top soils $(0-15 \mathrm{~cm})$ and soils at the subsurface $(65 \mathrm{~cm})$, both niches unexpectedly showed high alpha diversity and marked differences in the microbial community structure at phylum level (Figures 6-8) and relative abundance of lower taxonomic ranks and among the two most abundant phyla (Figure 7 and Figure 8).

Soil microorganisms are critically important for ecosystem functioning, carbon and nitrogen cycling; being responsible for most auto-lithotrophic metabolisms (nitrogen fixation and photosynthesis) needed for organic matter and soil fertility. So, the occurrence of a diverse group of bacteria in the samples is highly desirable. Although the Proteobacteria were numerically abundant, their operational diversity was quite limited (Figures 2-4). The bulk of the operational taxonomic units based on sequence data belong to less well-defined taxa labeled "others". The resilient Firmicutes were dominant in terms of relative numbers and operational entities. They contain a range of thermophilic, antibiotic and endospore producing members as well as phosphate solubilizing bio-inoculants. The reservoir of these naturally occurring and well adapted organisms is a good source for screening for elite strains such as bio-fertilizers and biopesticides for revegetation. The phylogenetic relationship of the majority of bacteria recovered from the environment is presented in Figure 7(a) and Figure 7(b).

\subsection{Abiotic Conditions and Biotic Influence}

The top soil was significantly hotter $(\mathrm{p}=0.001)$ and slightly more acidic than the 


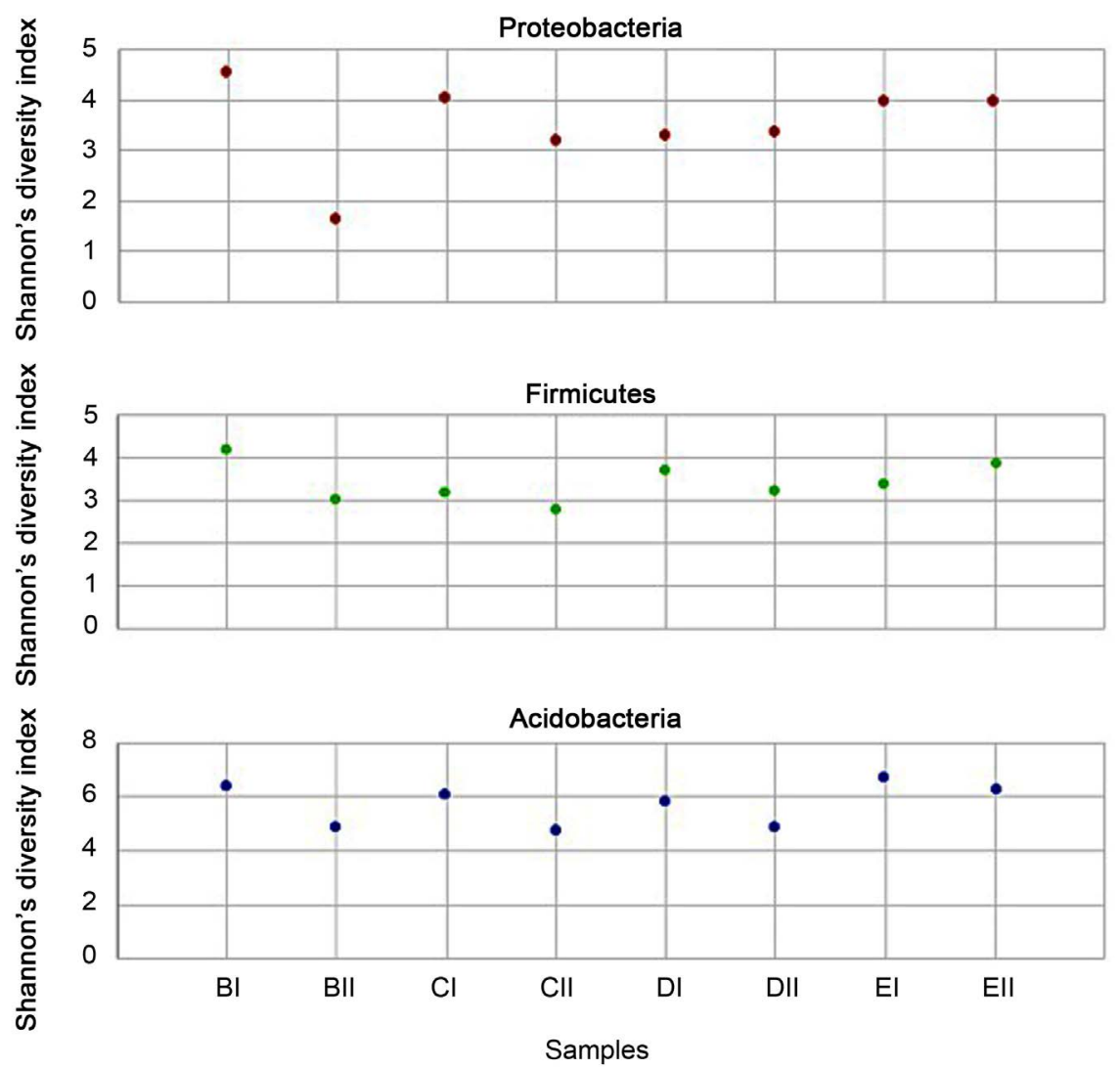

Figure 6. Variations in the Shannon diversity index of key bacteria phyla in top $15 \mathrm{~cm}$ and $65 \mathrm{~cm}$ semi-arid soil-layers (BI, CI, DI and EI, top soil; BII, CII, DII, and EII, sub layer $65 \mathrm{~cm})$.

subsoil at the depth sampled. There was a significant difference in moisture content as well (Table 1). The impact of these factors on microbial diversity have been well documented [20] [21] and could explain the observed differences. However, the geophysical impacts associated with depths could further explain the observed trends. The average moisture at the top soil at the time of the sample collection (May) was $0.08 \% \pm 0.02 \%$ while the sub soil showed $0.36 \% \pm$ $0.03 \%$ (Table 1 ) reflecting a significantly improved retention of moisture at the sub-surface and might explain the unusual rich diversity reported. Biocrust and hypolithic communities have been shown to increase soil fertility and moisture retention [13]. The short rainfall regimes in the semi-arid regions brings moisture to the soil for short periods but the moisture supplied to the soil is often offset by evaporation which is enhanced by the characteristic high winds and low relative humidity [22]. Due to poor vegetation cover, atmospheric temperature impacts directly on the soil surface, with an observed average top soil temperature of $45^{\circ} \mathrm{C} \pm 1.6^{\circ} \mathrm{C}$ (Table 1). Earlier reports [22] showed that air temperature is reasonably well reflected at the surface but disappear rapidly in depth and at $50 \mathrm{~cm}$ depths, eliminating daily variations with evident seasonal fluctuations. In this study, an average temperature of $32.2^{\circ} \mathrm{C} \pm 1.9^{\circ} \mathrm{C}$ at the subsurface depth of $65 \mathrm{~cm}$ was observed in comparison with scorching top soil temperature of $45^{\circ} \mathrm{C} \pm$ 


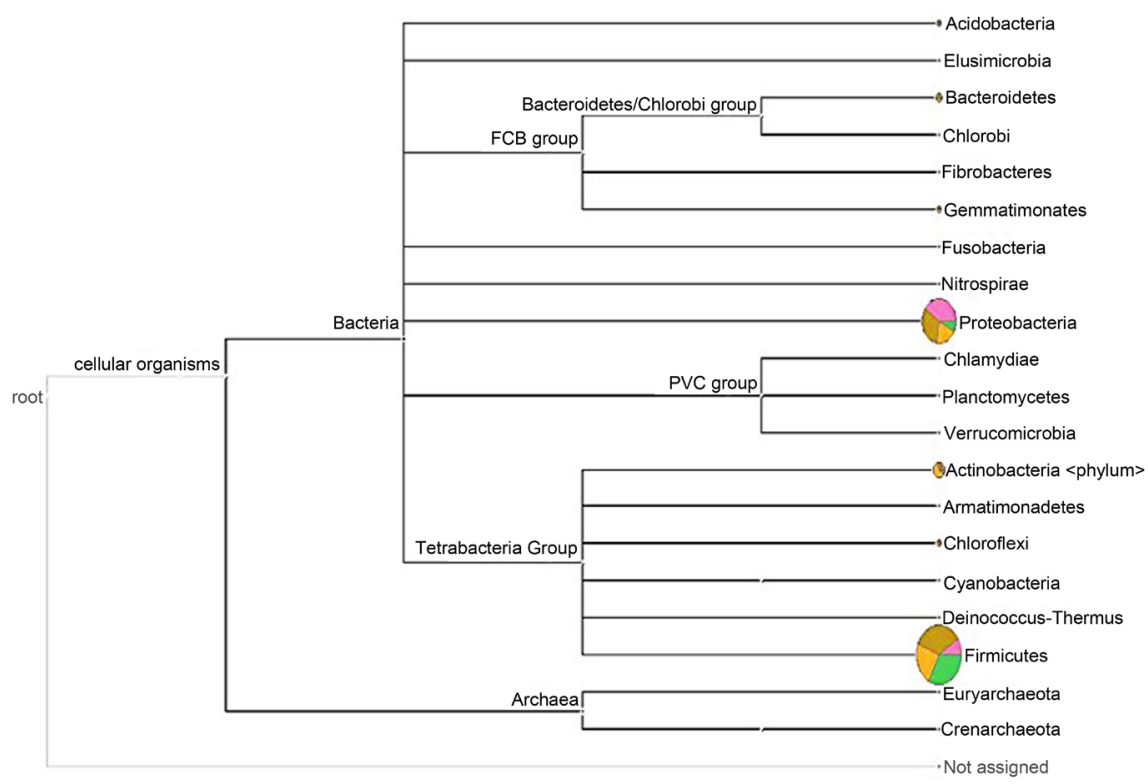

(a)

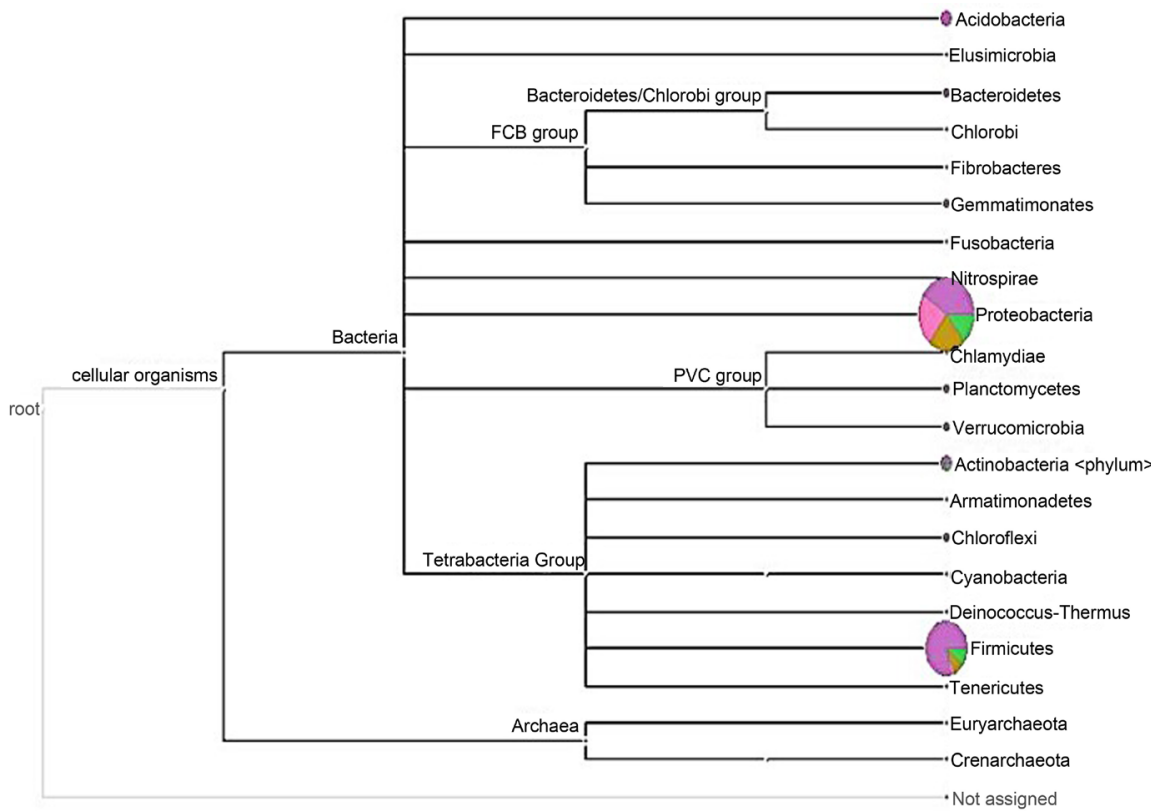

(b)

Figure 7. Phylogenic diversity at (a) top soil and (b) subsurface depth $(65 \mathrm{~cm})$. The top two phyla Proteobacteria and Firmicutes are indicated as pie charts at the terminal nodes with the diameter of each phyla representing their relative abundance. The same phylum consists of diverse and different bacteria at the top and sub soil depths studied.

$1.6^{\circ} \mathrm{C}$ which suggests that the sub-surface microbial communities are effectively shielded from the extreme conditions experienced at the surface.

Proteobacteria are ubiquitous bacteria, reported to be prominent members of desert soil bacterial communities [19] [23] with known metabolic diversity [24]. The abundance of the Proteobacteria in soils reflects their ability to thrive on diverse substrates as well as their functional role in nitrogen fixation, degradation 


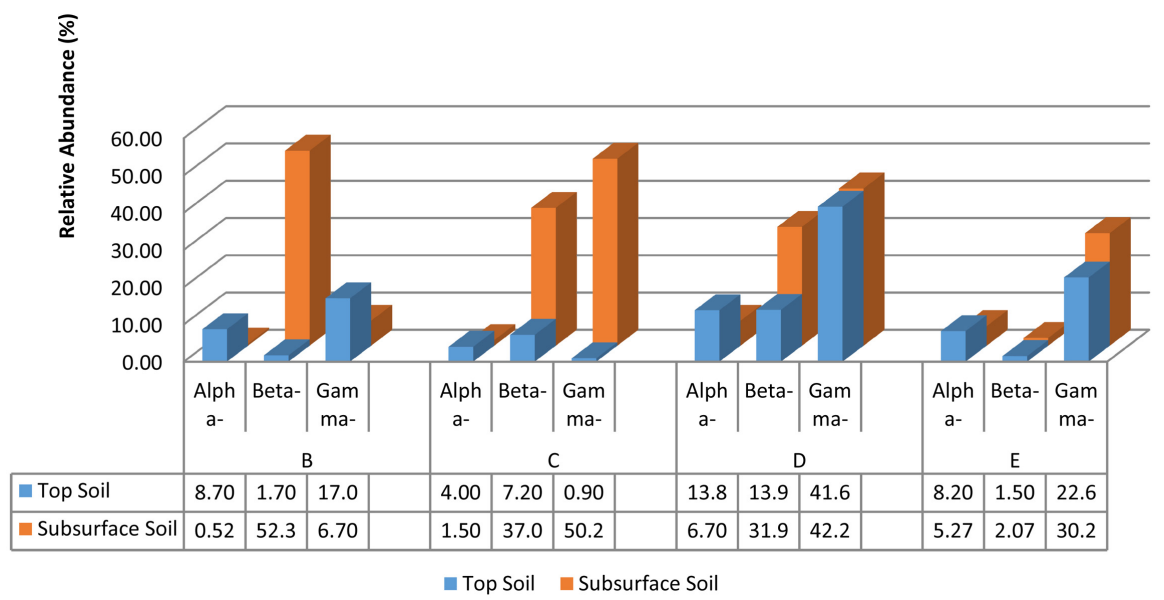

(a)

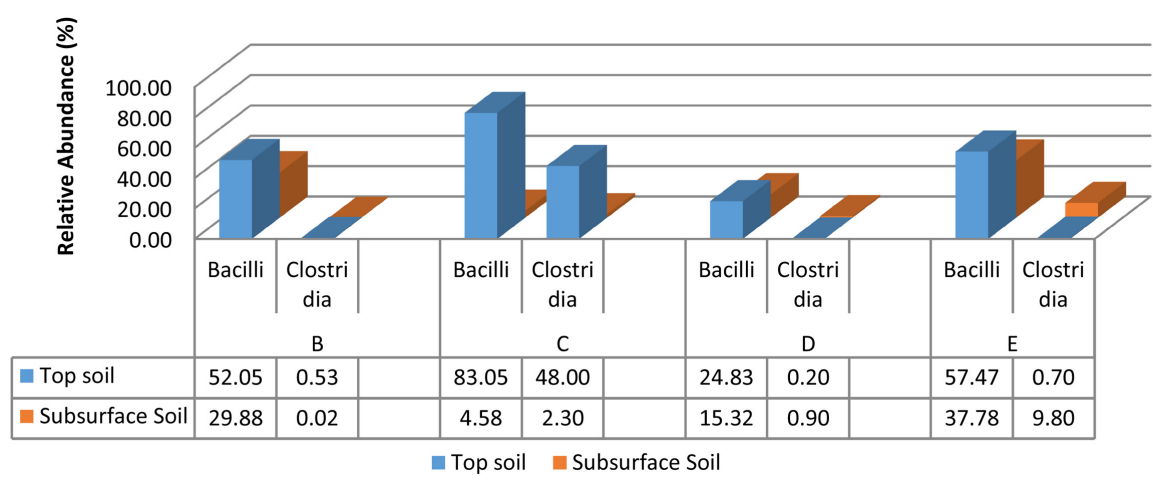

(b)

Figure 8. Distribution of Proteobacteria sub-phyla (a) and Firmicutes Phylun (b) across top soil and subsurface soil in semi-arid regions of Borno state. Only Alpha-, Beta-, and Gamma-, Proteobacteria sub-phylaobserved (a) while endospore-forming Bacilli and Clostridia constituted the majority of the Firmicutes (b).

of substrates and in biogeochemical cycles [24]. We observed that the sub-surface show slightly higher Proteobacteria population than at the topsoil (Figure 8(a)), even though these bacteria are usually more abundant in the top soil of humid climates where plant roots thrive and release rich organic matter. The prevailing extreme physical conditions (higher temperature and lower moisture) on the top soil in these environments appears to limit the population of these key fertility organisms. Their elevated population beneath the surface, would suggest that planting and transplantation exercises would achieve better results by increasing planting depth or providing shade and micro-irrigation for improved success. Studies on changes in bacterial community composition in a succession of semi-arid to desert habitats have shown that there is a broad gradient in microbial diversity and phylogenic composition of Proteobacteria that correlated strongly with soil relative humidity and temperature [20]. This is consistent with our findings although this study approached the relative humidity at different depths rather than across the geographical spread as shown in Figure 8. 
Among the Proteobacteria are chemolithoautotrophs, heterotrophs, and mixotrophs. They are subdivided into five classes (Alpha-, Beta-, Gamma-, Delta- and Epsilon-Proteobacteria [11] [24]) all of which, except Epsilon Proteobacteria have been identified in this study. Members of the, Beta-, and Gamma- sub-phyla of Proteobacteria are considered to be copiotrophs are more prevalent where resource availability is high such as in rhizosphere soils [12], both class have been identified at varying abundances across all samples in this study with Beta-Proteobacteria showing higher relative abundance in the subsurface soil, Alpha-Proteobacteria more abundant at the surface and Gamma-Proteobacteria were ubiquitous in top and sub-surface depths except for top soil in study site C (Figure 8(a)).

Agricultural practices in this region may strongly influence the population of Proteobacteria as leguminous plants forms the dominant cultivated crops in the semi-arid region. Changes in vegetation as well as intensive agricultural practices were shown to affect soil microbial community composition and activity. Although samples were collected from uncultivated soils, grasses, shrub cover and grazing activities could affect microbial populations significantly, it is unlikely that these factors impacted the sub-surface microbial community structure. Less abundant members of the bacterial community such as Acidobacteria, Actinobacteria and Bacteroidetes did not show significant variation in their relative abundances across depths although their presence may represent distinct functional responsibilities in the semi-arid soils. Many members of the Actinobacteria are antibiotic producers.

The Phylum Firmicutes is the second overall numerically most abundant bacterial group in these soils and were the most diverse in terms of number of OTUs (2780) (Table 3). Firmicutes are also well represented in desert and semi-arid soilsalthough most studies on bacterial composition in these regions across the globe show Actinobacteria, Bacteroidetes and Proteobacteria as most abundant [25] [26] [27] [28]. Bacilli and Clostridia are the two (2) distinct class of the Firmicutes identified in this study (Figure 8(b)) and is consistent with previous findings [27] [28]. There is a higher relative abundance of Firmicutes at the top soil across all samples (Figure 2, Figure 8(b)) with the genus Bacilli being the most dominant (Figure $8(\mathrm{~b})$ ). The high relative abundance of Firmicutes could be attributed to the resilience of these bacteria under harsh conditions. Many Firmicutes produce endospores that are extremely resistant to desiccation, heat and radiation, and can survive many extreme conditions for prolonged periods as dormant endospores. At the sub-surface, where physical conditions are most ambient for bacterial survival, they maintained a low relative abundance due perhaps to competition from other bacterial phyla and families.

\section{Conclusion}

The bacterial communities in these semi-arid soil samples are surprisingly highly diverse at both the top soil and sub-soil. The Proteobacteria and Firmicutes 
dominate the niche with members of the Acidobacteria and Actinobacteria occupying significant operational taxonomic realms. Although all bacteria phyla were detected in top soil and $65 \mathrm{~cm}$ depth, phylotypes at lower taxonomic ranks were strikingly different. The high diversity and richness of Proteobacteria, some of which are key to soil fertility at and below the class taxa in subsurface soils suggest that revegetation efforts should employ techniques to shift the gradient of these microbiota upwards (shades, moisture) to improve outcome. The distribution of major bacterial taxa in the semi-arid soils varied across depths. Soils in semi-arid regions in Nigeria contain numerous operational taxonomic bacterial groups with potential thermophilic and drought genetic resources to be mined. Microbial community structure beneath the top soil appears stable and should be the target sample for the assessments of climatic change impact on microbial community structure in environments like this.

\section{Acknowledgements}

This work was supported in part by FAU Faculty Sabbatical Grant, and OURI grants to RR and NE. Cost for sequencing and analysis was covered by Florida Atlantic University Faculty professional development grant to NE and graduate teaching assistance-ship to KD. This work was also supported in part by the Biotechnology Centre, University of Maiduguri support to BM.

\section{Conflicts of Interest}

The authors declare no conflicts of interest regarding the publication of this paper.

\section{References}

[1] Makhalanyane, T.P., Valverde, A., Gunnigle, E., Frossard, A., Ramond, J.B. and Cowan, D.A. (2015) Microbial Ecology of Hot Desert Edaphic Systems. FEMS Microbiological Review, 39, 203-221. https://doi.org/10.1093/femsre/fuu011

[2] Neilson, J.W., Quade, J., Ortiz, M., Nelson, W.M., Legatzki, A., Tian, F., et al. (2012) Life at the Hyper-Arid Margin: Novel Bacterial Diversity in Arid Soils of the Atacama Desert, Chile. Extremophiles, 16, 553-566. https://doi.org/10.1007/s00792-012-0454-z

[3] Maestre, F.T., Delgado-Baquerizo, M., Jeffries, T.C., Eldridge, D.J., Ochoa, V., Gozalo, B., Quero, J.L., García-Gómez, M., et al. (2015) Increasing Aridity Reduces Soil Microbial Diversity and Abundance in Global Drylands. Proceedings of the National Academy of Sciences of the United States of America, 112, 15684-15689. https://doi.org/10.1073/pnas.1516684112

[4] Bellard, C., Bertelsmeier, C., Leadley, P., Thuiller, W. and Courchamp, F. (2012) Impacts of Climate Change on the Future of Biodiversity. Ecology Letters, 15, 365-377. https://doi.org/10.1111/j.1461-0248.2011.01736.x

[5] Cardinale, B.J., Duffy, E., Gonzalez, A., Hooper, D.U., Perrimgs, C., Vanail, P., et al. (2012) Biodiversity Loss and Its Impact on Humanity. Nature, 486, 59-67. https://doi.org/10.1038/nature11148

[6] Peñuelas, J., Sardans, J., Estiate, M., Ogaya, R., Carnicer, J., et al. (2013) Evidence of 
Current Impact of Climate Change on Life: A Walk from Genes to the Biosphere. Global Change Biology, 19, 2303-2338. https://doi.org/10.1111/gcb.12143

[7] Reynolds, J.F., Smith, D.M.S., Lambin, E.F., Turner, B.L., Mortimore, M., Batterbury, S.P.J., et al. (2007) Global Desertification: Building a Science for Dryland Development. Science, 316, 847-851. https://doi.org/10.1126/science.1131634

[8] Millennium Ecosystem Assessment (MEA) (2005) Ecosystems and Human Well-Being: Desertification Synthesis. World Resources Institute, Washington DC.

[9] Fierer, N., Leff, J.W., Adams, B.J., Nielsen, U.N., Bates, S.T., Lauber, C.L., Owens, S., Gilbert, J.A., Wall, D.H. and Caporaso, J.G. (2012) Cross-Biome Metagenomics Analyses of Soil Microbial Communities and Their Functional Attributes. Proceedings of the National Academy of Science USA, 109, 21390-21395. https://doi.org/10.1073/pnas.1215210110

[10] Bundt, M., Widmer, F., Pesaro, M., Zeyer, J. and Blaser, P. (2001) Preferential Flow Paths Biological "Hot Spots" in Soils. Soil Biology and Biochemistry, 33, 729-738. https://doi.org/10.1016/S0038-0717(00)00218-2

[11] Thulani, P., Makhalanyane, A.V., Eoin, G., Aline F., Jean-Baptiste, R. and Cowan, D.A. (2015) Microbial Ecology of Hot Desert Edaphic Systems. FEMS Microbiology Reviews, 39, 203-221. https://doi.org/10.1093/femsre/fuu011

[12] Dawkins, K. and Esiobu, N. (2017) Arbuscular and Ectomycorrhizal Fungi Associated with the Invasive Brazilian Pepper Tree (Schinus terebinthifolius) and Two Native Plants in South Florida. Frontiers in Microbiology, 8, 665-672. https://doi.org/10.3389/fmicb.2017.00665

[13] Bates, S.T., Berg-Lyons, D.B., Caporosa, J.G., Walters, W.A., Knight, R. and Fierer, N. (2011) Examining the Global Distribution of Dominant Archaeal Populations in Soils. The ISME Journal, 5, 908-917. https://doi.org/10.1038/ismej.2010.171

[14] Sambrook, J., Fritsch, E.F. and Maniatis, T. (1989) Molecular Cloning: A Laboratory Manual. Cold Spring Harbor Laboratory, Cold Spring Harbor, NY.

[15] Caporaso, G., Christian L., William, A.W., Donna, B.G., James, H., Fierer, N., et al. (2012) Ultra-High-Throughput Microbial Community Analysis on the Illumina HiSeq and MiSeq Platforms. ISME Journal, 6, 1621-1624. https://doi.org/10.1038/ismej.2012.8

[16] Caporaso, J.G., Kuczynski, J., Stombaugh, J., Bittinger, K., Bushman, F.D., Costello, E.K., Fierer, N., et al. (2010) QIIME Allows Analysis of High Throughput Community Sequencing Data. Nature Methods, 7, 335-336.

https://doi.org/10.1038/nmeth.f.303

[17] Huson, D.H., Auch, A.F., Qi, J. and Schuster, S.C. (2007) MEGAN Analysis of Metagenomic Data. Genome Research, 17, 377-386. https://doi.org/10.1101/gr.5969107

[18] Bik, H.M. (2014) Phinch: An Interactive, Exploratory Data Visualization Framework for Omic Datasets. https://doi.org/10.1101/009944

[19] Lefever, C.T., Viloria, N., Schmidt, M.L., et al. (2012) Novel Magnetite Producing Magnetotactic Bacteria Belonging to the Gammaproteobacteria. ISME Journal, 6, 440-450. https://doi.org/10.1038/ismej.2011.97

[20] Neilson, J.W., Califf, K., Cardona, C., Copeland, A., van Treuren, W., Josephson, K.L., Knight, R, et al. (2017) Significant Impacts of Increasing Aridity on the Arid Soil Microbiome. mSystems, 2, e00195. https://doi.org/10.1128/mSystems.00195-16

[21] Lauber, C., Knight, R., Hamady, M. and Fierer, N. (2009) Soil pH as a Predictor of Soil Bacterialcommunity Structure at the Continental Scale: A Pyrosequencing-Based Assessment. Applied Environmental Microbiology, 75, 5111-5120. 
https://doi.org/10.1128/AEM.00335-09

[22] Verheye, W. (2008) Soils of Arid and Semi-Arid Regions. In: Verheye, W.H., Ed., Land Use, Land Cover and Soil Sciences, UNESCO-EOLSS Publishers, Oxford, 67-95.

[23] Chen, W.M., Moulin, L., Bontemps, C., et al. (2003) Legume Symbiotic Nitrogen Fixation by Beta-Proteobacteria Is Widespread in Nature. Journal of Bacteriology, 185, 7266-7272. https://doi.org/10.1128/JB.185.24.7266-7272.2003

[24] Aislabie, J. and Deslippe, J.R. (2013) Soil Microbes and Their Contribution to Soil Services. In: Dymond, J.R., Ed., Ecosystems Services in New Zealand Conditions and Trends, Manaaki Press, Lincoln, 143-161.

[25] Pointing, S.B. and Belnap, J. (2012) Microbial Colonization and Controls in Dryland Systems. Nature Reviews Microbiology, 10, 551-562. https://doi.org/10.1038/nrmicro2831

[26] Chanal, A., Chapon, V., Benzerara, K., Barakat, M., Christen, R., et al. (2006) The Desert of Tataouine: An Extreme Environment That Hosts a Wide Diversity of Microorganisms and Radiotolerant Bacteria. Environmental Microbiology, 8, 514-525. https://doi.org/10.1111/j.1462-2920.2005.00921.x

[27] Lester, E.D., Satomi, M. and Ponce, A. (2007) Microflora of Extreme Arid Atacama Desert Soils. Soil Biology and Biochemistry, 39, 704-708.

https://doi.org/10.1016/j.soilbio.2006.09.020

[28] Fierer, N., Bradford, M.A. and Jackson, R.B. (2007) Toward an Ecological Classification of Soil Bacteria. Ecology, 88, 1354-1364. https://doi.org/10.1890/05-1839 